\title{
Methods of Analyzing Nonstationary Variability of the Black Sea Wave Climate
}

\author{
Ya. V. Saprykina*, S. Yu. Kuznetsov \\ Shirshov Institute of Oceanology, Russian Academy of Sciences, Moscow, Russian Federation \\ *e-mail: saprykina@ocean.ru
}

Based on the data of Voluntary Observing Ship (VOS) Program of the Black Sea waves in 19502007, the wave climate variability and its relation to the main climatic indices is analyzed by the example of the maximum annual wave heights. Climatic indices characterizing the North Atlantic, Atlantic Multi-Decadal and Pacific Decadal oscillations, as well as fluctuations of the East AtlanticWestern Russia teleconnection pattern are considered. It is shown that the methods based on the wavelet analysis, particularly the spavlet analysis and the method of the wavelet correlations proposed by the authors, have doubtless advantages since they permit to reveal fine structure of the nonstationary process in variability both of the wave heights and the climatic indices, the features of various fluctuations' periods, and to analyze relationships between the climatic indices' changes and the wave heights. Due to these methods, determined are the main periods of variability in the anomalies of the maximum annual wave heights associated with a) the North Atlantic Oscillation (about 28-25, 14-16 and 6-6.5 years); b) the Atlantic Multi-Decadal Oscillation (50, 25 and about 14-16 years); c) the Pacific Decadal Oscillation (about 12.5-10 years) and d) the East AtlanticWestern Russia pattern fluctuation (about 66-67, 14-16 and 7-7.5 years). Significant low-frequency impact of fluctuations of the East Atlantic-Western Russia teleconnection pattern upon the Black Sea wave climate is shown for the first time.

Keywords: the Black Sea, wave climate, the North Atlantic Oscillation, the Atlantic Multi-Decadal Oscillation, the Pacific Decadal Oscillation, the East Atlantic-Western Russia teleconnection pattern, wavelet analysis methods, spavlet analysis, maximum wave height, climate change.

Acknowledgements: the research was carried out within the framework of the FASO (Russia) State Order (No. 0149-2018-0015) under partial support of RFFI (Project No. 16-15-76002 ЭPA_a, BS STEMA).

For citation: Saprykina, Ya.V. and Kuznetsov, S.Yu., 2018. Methods of Analyzing Nonstationary Variability of the Black Sea Wave Climate. Physical Oceanography, [e-journal] 25(4), pp. 317-329. doi:10.22449/1573-160X-2018-4-317-329

DOI: $10.22449 / 1573-160 X-2018-4-317-329$

(C) 2018, Ya. V. Saprykina, S. Yu. Kuznetsov

(C) 2018, Physical Oceanography

\section{Introduction}

Wave climate variability is one of the key issues being important for solving the problems associated with ensuring safe economic activity in the seas and oceans (for example, navigation and fishing) and with the elaboration of an optimal long-term strategy for the development of coastal areas (for example, protecting the shores from wave action) .

Recent studies showed that fluctuations in the large-scale atmospheric circulation characteristics, determined by climatic indices, such as the North Atlantic Oscillation (NAO), Atlantic Multi-decadal (AMO) and Pacific Decadal Oscillation (PDO), have a significant effect on the regional storm activity variation and accordingly - on the wave heights and morphodynamics of the shores [1-8]. 
Analysis of variability of intensity of the storms near the Danube delta, obtained from model wave data based on wind field reanalysis, showed that there is the pronounced intra-annual seasonal variability, as well as variability in the 4-10 year periods associated with fluctuations in the North Atlantic oscillation [9]. The authors associated the storm intensity reduction in the $2000 \mathrm{~s}$ with the lowfrequency variability of the East Atlantic - Western Russia (EA/WR) oscillations [9]. Long-term fluctuations (of the order of 40-50 years) of maximum annual wave heights were identified in [4-10] according to the data of long-term observations of Ukraine hydrometeorological stations in the Black Sea. It was shown that they can be associated with changes in the Atlantic Multi-decadal and Pacific Decadal Oscillation.

The main problem in analyzing the low-frequency variability of the wave climate is wave data. Data of long-term field observations, which are very limited, generally are the property of hydrometeorological services having their stations on the shore. Consequently, the wave heights are recorded mainly in the coastal part. There are also no data of long-term continuous (more than 20 years) full-scale instrumental observations of waves in the open sea. Therefore, for this type of analysis, the data of numerical simulation, which may contain errors related to the accuracy of the reanalysis of wind fields, are primarily used. For example, as shown in [11], periodic fluctuations in the model data analysis can have a time shift as compared with fluctuations of the same period determined from the data of field measurements. The fluctuations of larger periods (more than 40 years) are poorly reproduced by model data.

Another major problem in the analysis of low-frequency fluctuations in the wave climate is the relatively short-term series of wave data available, which classical analytical methods, for example the spectral ones, may not be applicable to. New techniques are also necessary for reliable study of the process periodicity.

The principal aim of the present study is to identify the links between wave climate variation and the fluctuations in the indices of climatic variability and to carry out a comparative analysis of the results obtained by different methods based on longterm data array of associated in-situ ship observations of the wave heights in the Black Sea. The main attention will be paid to the long-term periodicity (low-frequency variability) analysis for a period of 10 years and more.

\section{Discussion of the methods and results obtained}

A database of long-term associated ship meteorological observations was used for the wave climate analysis. It included the visual registration of altitudes and periods, carried out within the Voluntary Observing Ship Program. More details of the scheme of such observations are available on the website: http://www.vos.noaa.gov/vos_scheme.shtml. According to the observations of the ships, the parameters of wind waves and swell (waves observed in the absence of wind or not associated with the available wind effect) are recorded separately. Despite the fact that this data was obtained in a visual way, as shown in [12], they are quite adequate to the data of instrumental measurements. A wave atlas was created at the Institute of Oceanology of the Russian Academy of Sciences based on the data of associated ship observations $[13,14]$. 
For the Black Sea area, the data on the wave heights for 1950-2007 with steepness (the ratio of height to wavelength) less than 0.1 , total 125,142 data was selected. Further, to analyze the extreme wave climate variability, the heights of the highest waves in each year were chosen. The heights of wind waves and swell waves were studied separately.

In accordance with the technique proposed in $[4,10]$, to standardize the data of visual observations, a normalization aimed to obtain anomalies of the maximum annual wave heights was carried out by the following formula

$$
A_{i}=\left(H_{i}-\operatorname{mean}(H)\right) / \operatorname{std}(H),
$$

where $H_{i}$ is the maximum annual wave height, $i$ is the year; mean - mean whole range of heights over the considered time period; std is the standard deviation. Then, fluctuations in the anomalies of the maximum annual wave heights and their relationship to fluctuations in climatic indices were analyzed.

Fig. 1 shows the changes of the anomalies of the maximum annual heights of wind waves and swell. It is clearly seen that the anomalies of wave heights are much larger in the 1970-1980 period, but starting from about 1983 a sharp decrease took place. This qualitatively well coincides with changes of the wave anomalies obtained from hydrometeorological observations of the southern coast of the Black Sea $[4,10]$. It was shown that such a low-frequency fluctuation of the maximum annual wave heights can be related to the mutual influence of the longterm periodicity of the Atlantic Multi-decadal (50 years) and Pacific Decadal (40 years) Oscillation.

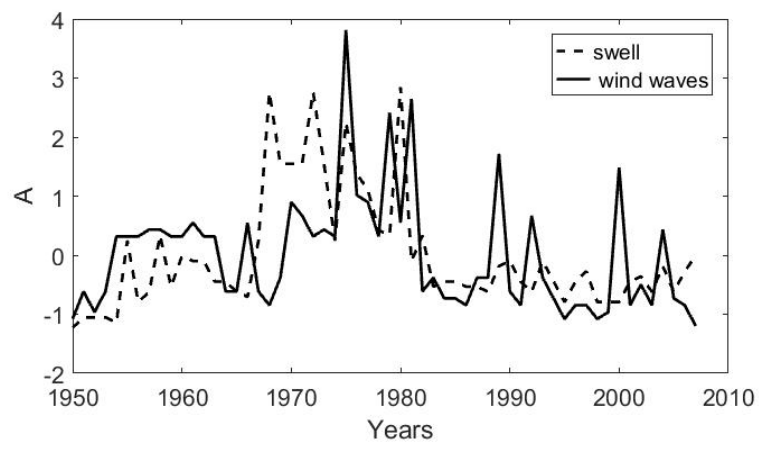

Fig. 1. Change of the anomalies (A) of the maximum annual wave heights

To detect periodic changes in the anomalies of the maximum annual wave heights, spectral analysis using the Yule-Walker parametric method was carried out. This method is successfully applied in statistics for the processing of short data series. The method is based on applying to the data series an autoregression model in which the studied variable linearly depends on its own previous values and on some stochastic term [15]. For example, this method allows determining the period of a sinusoidal series along a length of half this period. Wavelet analysis (using the Morlet wavelet function [16]) was used to reveal the detailed structure of fluctuations in the anomalies of the maximum annual wave heights [16]. It is a kind of a sweep of the studied series in terms of frequencies, permitting to analyze the structure of nonstationary processes $[6,17]$. 
Fig. 2 shows the wavelet diagrams and parametric spectra of changes of the anomalies of the maximum annual heights of wind and swell waves. It is clearly seen that the fluctuations of the anomalies are nonstationary, they have somewhat different structure. Along with constant close frequency scales of the order of 0.0221 /year for wind waves and 0.024 1/year for swell waves, there are clearly pronounced trends of frequency increase or decrease with time (visible inclined ridges on the wavelet transformation), which cannot be reflected in the spectra (Fig. 2). So, the frequency scale present in the spectrum of wind waves is 0.171 /year within the analyzed period of 1950-2007 the trend is to reduce the frequency, and the frequency scales $0.06-0.081$ /year - the trend to increase the frequency. A frequency scale of 0.0851 /year close to them in the swell spectrum also has a trend to increase, and the frequency scale of 0.061 /year, which is clearly visible on the wavelet diagram, is not distinguished by spectral analysis methods.
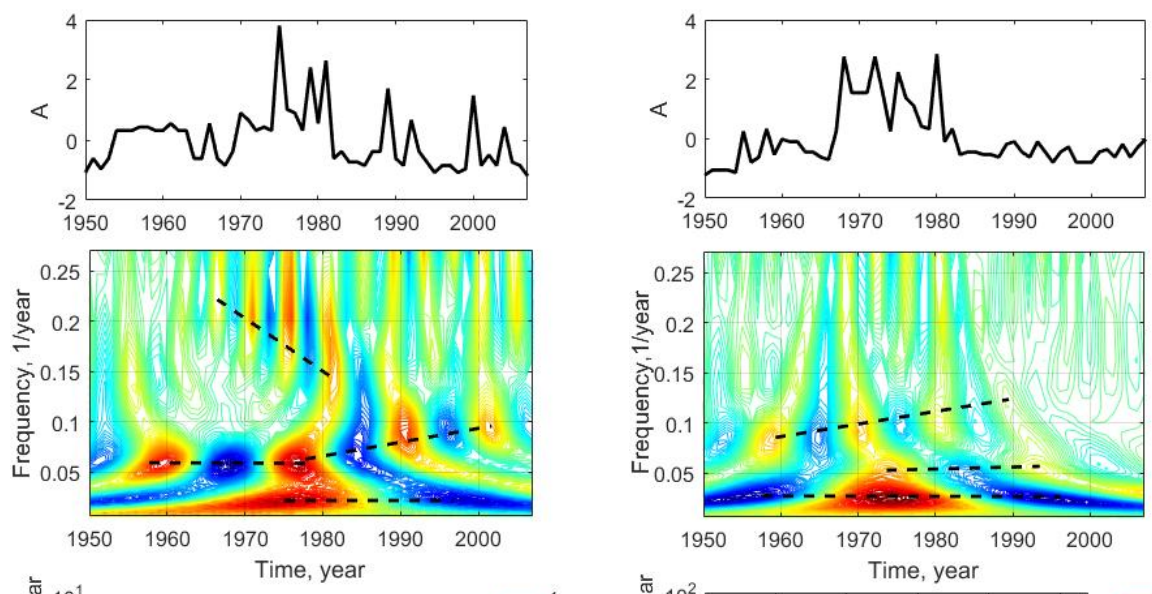

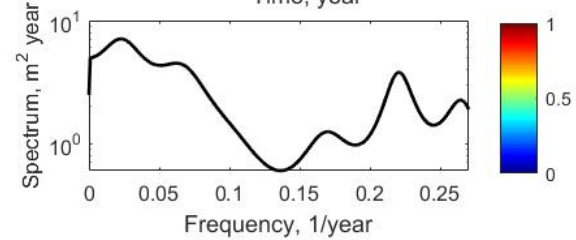

$a$

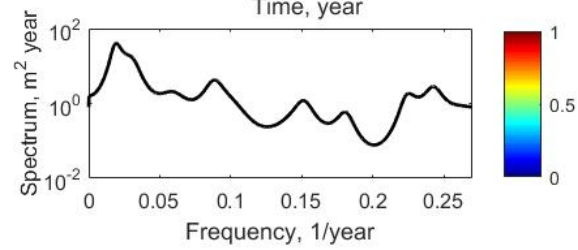

$b$

Fig. 2. Change of the anomalies of the maximum annual wave heights (above), their wavelet transformation (in the middle) and spectrum (below) for the heights of wind (a) and swell $(b)$ waves. The color scale corresponds to the wavelet-coefficient values

To analyze the climatic variability of the maximum wave heights, the coupling of the fluctuations of their anomalies with the North Atlantic, Atlantic Multi-Decadal and Pacific Decadal Oscillations, as well as with the fluctuation of the East AtlanticWestern Russia Oscillation was considered. Values of dimensionless climatic indices describing changes in vibrations calculated by certain methods were taken from the web-page of the National Oceanic \& Atmospheric Administration of the USA (URL: https://www.esrl.noaa.gov/psd/data/climateindices/list/).

Climatic indices, their wavelet transformations and parametric spectra are presented in Fig. 3. Changes of all the given indices, as well as the anomalies of wave heights, are nonstationary. There are frequency scales with trends for increasing or 320

PHYSICAL OCEANOGRAPHY VOL. 25 ISS. 4 (2018) 
decreasing the frequency. The nonstationarity of the process is not reflected in the spectra and leads to the fact that in some cases the characteristic energy-bearing frequencies, which are clearly visible on the wavelet diagrams, are not distinguished by spectral analysis methods.
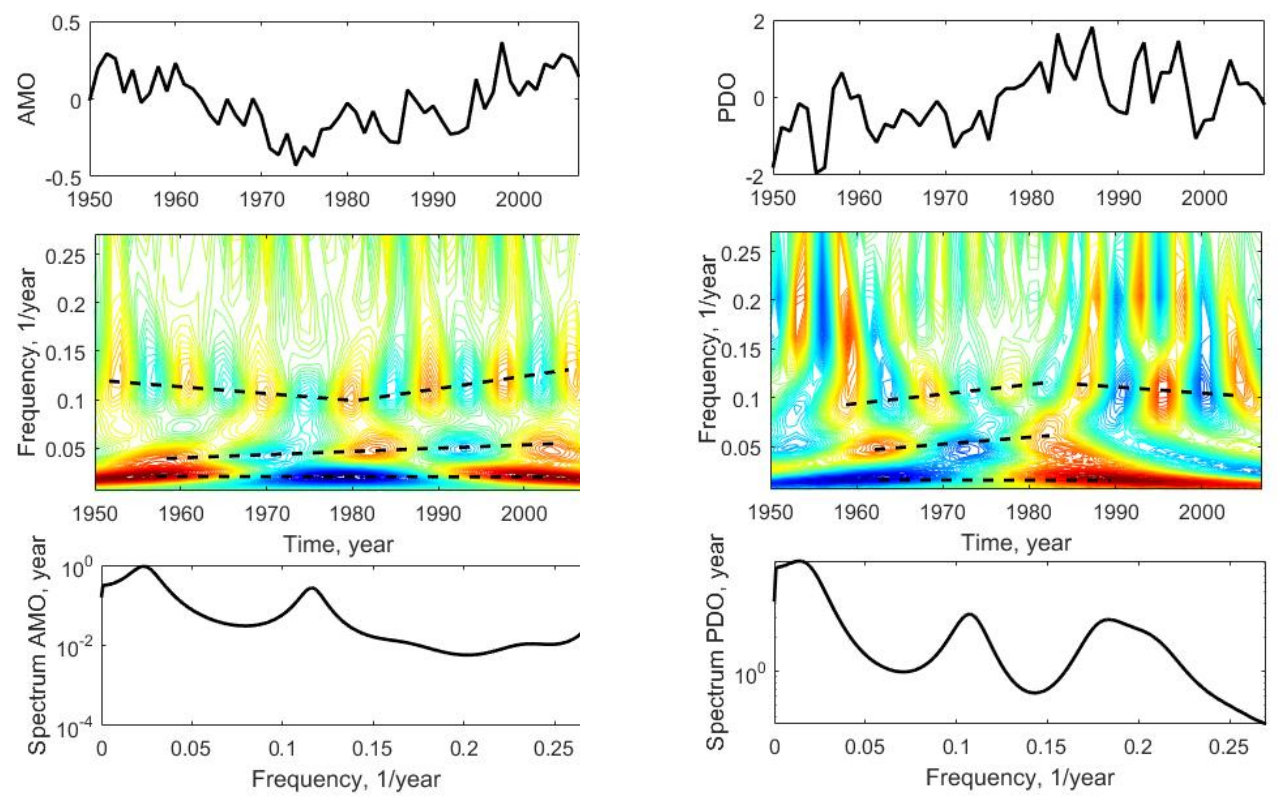

$a$
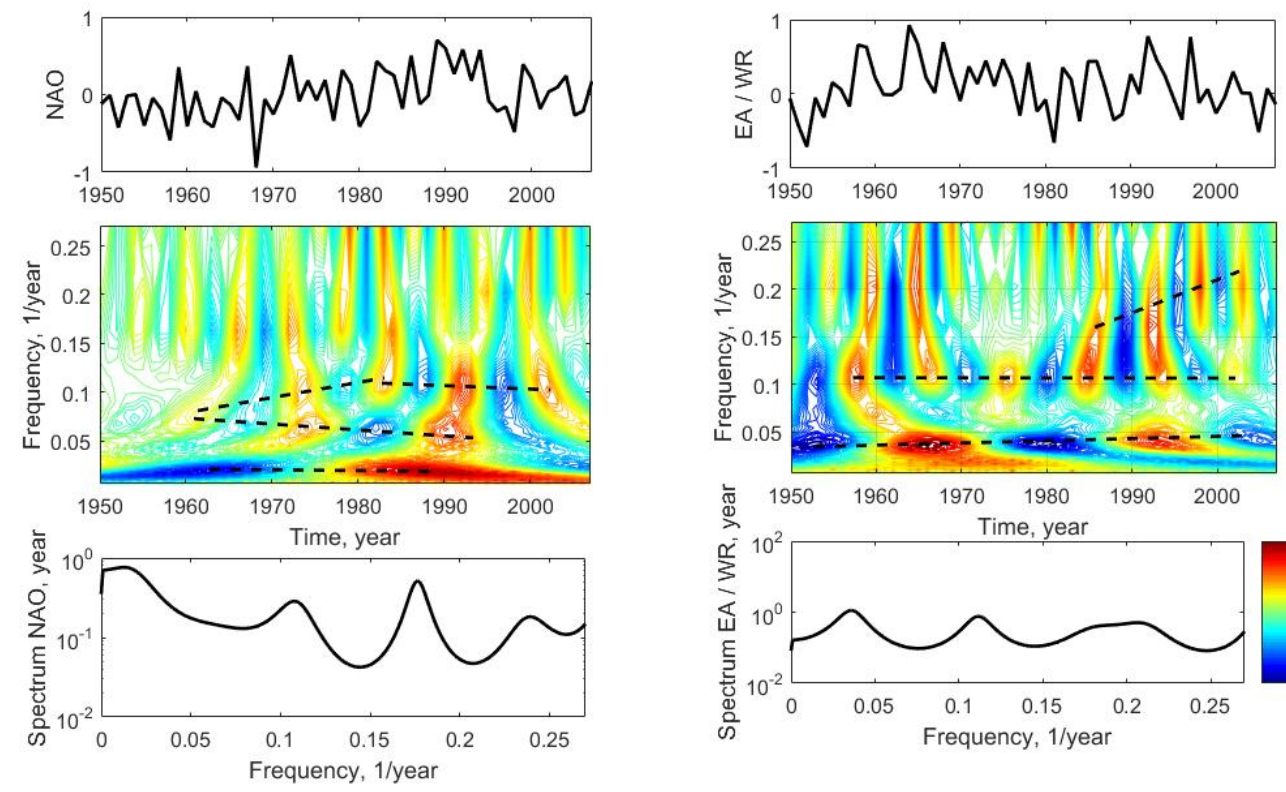

C

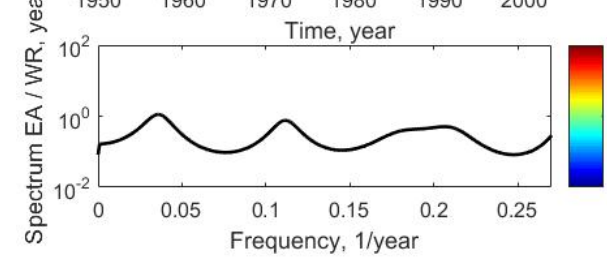

$d$

Fig. 3. Change of climatic indices (above), their wavelet transformation (in the middle) and spectrum (below) for the Atlantic Multi-Decadal (a), Pacific Decadal (b), North Atlantic (c) and East AtlanticWestern Russia $(d)$ oscillations. The color scale corresponds to the wavelet-coefficients' values 
Arguably, the changes of the anomalies of the maximum annual wave heights and indices are nonstationary, they are not analyzed in detail by the parametric spectral analysis methods. According to spectral and wavelet analysis, lowfrequency oscillations of all indices differ slightly. For $A M O$, the characteristic frequency scale is 0.022 1/year, for $N A O$ and $P D O-0.015$ 1/year, for $E A / W R-$ $0.0351 /$ year. For all the indices spectral analysis identifies the same peak at a frequency of 0.11 1/year, but wavelet analysis shows different trends of this frequency variation with time. There are also peaks at frequency scales of 0.170.2 1/year for $P D O, N A O$ and $E A / W R$, which also have different trends. Spectra are not distinguished by peaks that are clearly visible on wavelet diagrams at frequencies of 0.05 1/year (for $A M O$ and $P D O$ ) and 0.061 year (for NAO). The peaks in the spectra of climatic indices and the anomalies of the maximum annual wave heights, except for the lowest frequency of 0.022 1/year, do not coincide with the peaks of the spectra of the indices. Consequently, the linear relation between these series and the corresponding correlation coefficients for high-frequency components should be small.

However, a visual comparison of the wavelet diagrams shows that changes of the anomalies of the maximum annual wave heights in their structure have similar frequency scales and trends to all climatic indices. In this case, the structure of the wavelet diagram of the anomalies of the maximum annual swell heights has an obvious similarity to the structure of the wavelet diagrams of the $A M O$ (characteristic frequency 0.022 1/year) and NAO indices (increasing frequency $0.081 /$ year). The structure of the wavelet diagram of wind anomalies waves are similar with the structure of wavelet diagrams of the $P D O$ (characteristic frequency scale 0.015 1/year), $A M O$ and $N A O$ indices (characteristic frequency scale 0.061 year). According to the comparison of wavelet diagrams, changes of the anomalies of the maximum annual heights of wind waves and swell in the frequency range 0.17-0.18 1/year can be associated with changes in the EA/WR index.

A detailed analysis of the structure of nonstationary processes for the identification of a detailed connection between them can be carried out using the spavlet analysis method--construction the spectra of the wavelet coefficient modules of each frequency scale of the wavelet transformation [18, 19]. The lowfrequency components of the wavelet-coefficient modules represent an analog of the envelope components of the narrow frequency range signal centered on the wavelet frequency of a given scale.

Fig. 4 shows the spavlets of climatic indices. Spavlets of the anomalies of the maximum annual heights of wind waves and swell are demonstrated in Fig. 5.

Spavlet-analysis of fluctuations of climatic indices clearly shows the presence of low-frequency modulations of practically all scales of the wavelet transformation (Fig. 4). In the figure they appear as a ridge parallel to the axis of frequencies at pseudo-frequencies (spavlet frequencies) 0.015-0.025 1/year. Similar modulations are also present in the structure of the anomalies of the maximum annual wave heights (Fig. 5).

Presence of amplitude-modulated fluctuations explains the discrepancy between spectral peaks in the spectra of waves and in the spectra of climatic indices. If a nonlinear connection between the anomalies of the maximum annual 
wave heights and the indices is assumed, the nonlinear transformation of the indices containing amplitude-modulated oscillations will lead to the appearance of the peak heights of the peaks at combination (total and difference) frequencies in the spectra of the anomalies and to the absence of peaks in the spectra of climatic indices. This statement will be considered in more detail by analyzing the changes of the anomalies of the maximum annual swell heights and the $A M O$ index.

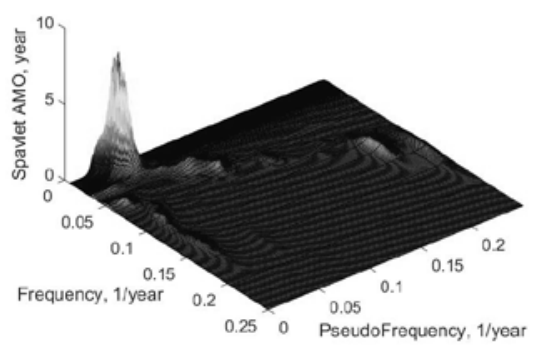

$a$

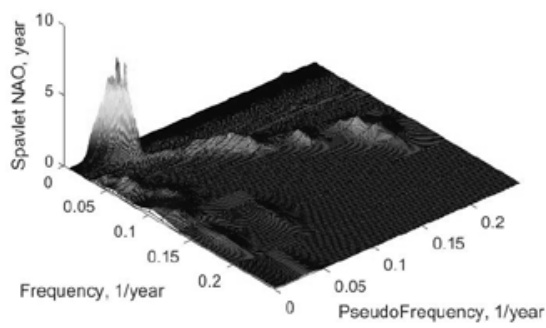

C

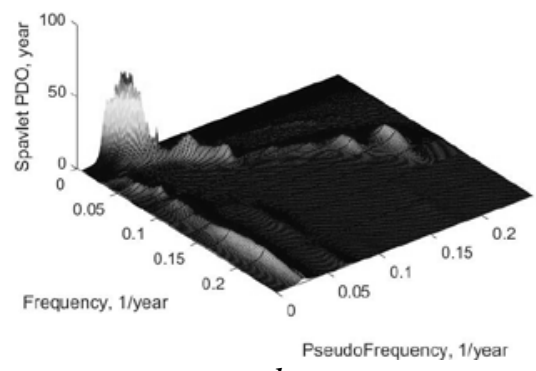

$b$

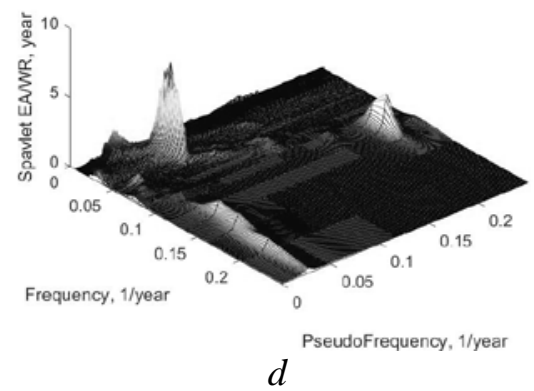

Fig. 4. Spavlets of the Atlantic Multi-Decadal (a), Pacific Decadal (b), North Atlantic (c) and East Atlantic-Western Russia (d) oscillations

Multi-decadal fluctuations of $A M O$ index consist of the sum of low-frequency component $f_{1}=0.021 /$ year and modulated in amplitude by it $f_{2}=0.121 /$ year component visible on a spectrum as two close peaks at 0.11 and $0.131 /$ year frequencies (Fig. 6). If we perform a non-linear transformation of this signal, for example, squaring it and subtracting the average, we get a signal containing many combinational frequencies and second multiple harmonics. Its spectrum is close to the observed one of the anomalies of maximum annual swell heights. The mentioned spectra of anomalies and the square of AMO index are shown in Fig. 6. It can be seen that at qualitative level their form coincides and this confirms the validity of proposed model.

Comparison of spavlet-transformations of climate indices and anomalies of the maximum annual wind wave heights also shows that the structure of non-stationary process of their change contains the elements of variation structure of all the indices - NAO, AMO, PDO, EA/WR and the variation structure of anomalies of the 
maximum annual swell wave heights mostly contains the elements of variation structure of $A M O$ and $N A O$ indices.
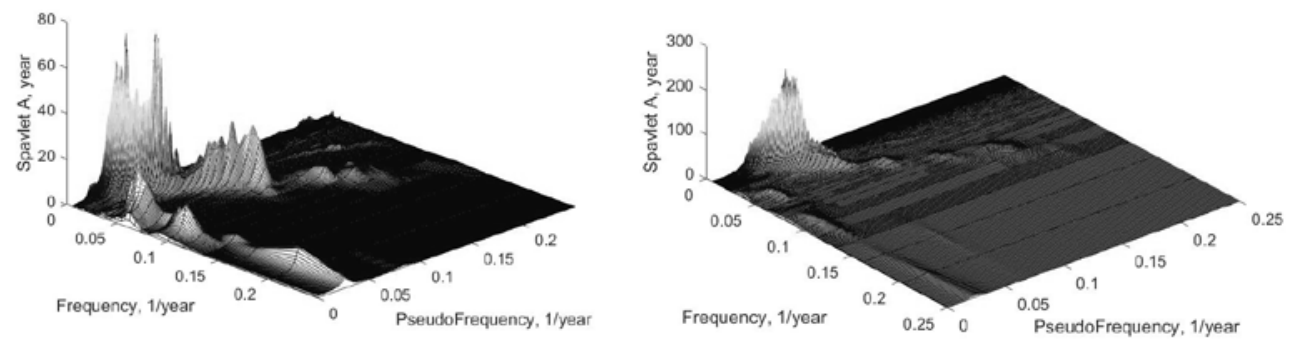

Fig. 5. Spavlets of the anomalies (A) of the maximum annual heights of the wind (above) and swell (below) waves

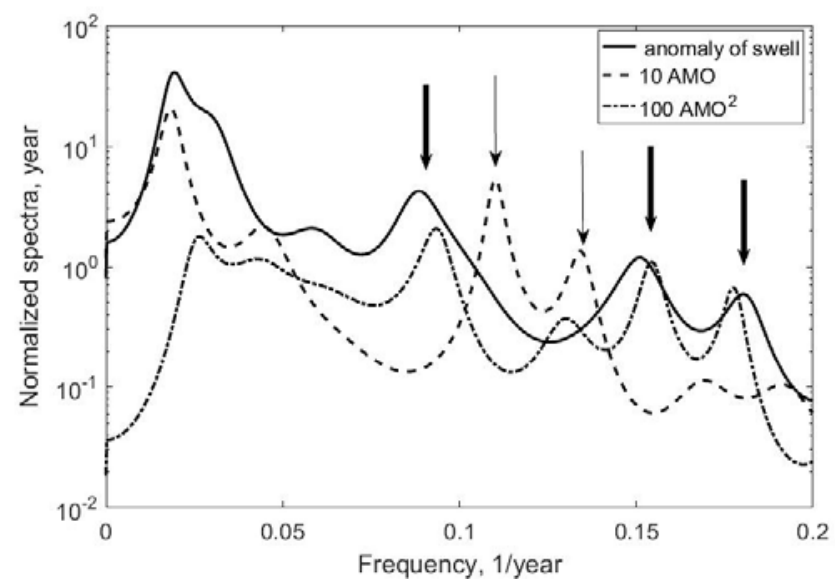

Fig. 6. Comparison of the Atlantic Multi-Decadal Oscillation spectra and the anomalies of the maximum annual heights of the swell waves

Non-stationary character of the change of indices and anomalies of the maximum wave heights does not provide a possibility for direct application of classical correlation analysis method in order to determine the relationships between them. This explains low values of cross-correlation function (not more than 0.5), particularly, at a zero time shift (Fig. 7). Moreover, as the changes in the indices and anomalies of the maximum annual wave heights are quasi-periodic, the correlation function does not decay in time. Together with the presence of trends in the change of the main periods, this results in the fact that relatively high values of the correlation coefficients can be observed with a significant time shift (Fig. 7).

Thus, classical correlation analysis shows that the changes in the anomalies of the maximum annual heights of both wind waves and swell ones are largely related with $N A O$ (the maximum correlation coefficient is 0.45 ), $A M O$ (the maximum correlation coefficients are 0.40 and 0.56 , respectively) and $P D O$ (the maximum correlation coefficients are 0.40 and 0.46 , respectively). Correlation coefficient with $E A / W R$ index is small, $0.30-0.37$. 

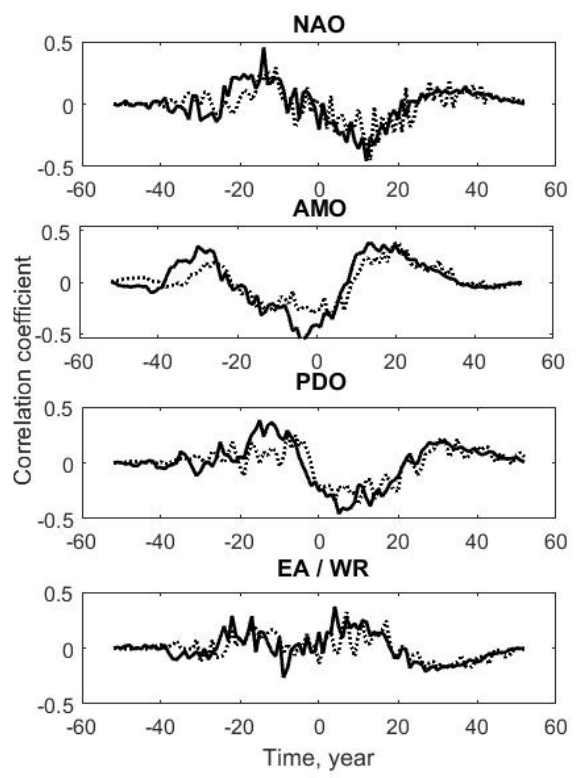

Fig. 7. Correlation functions between the anomalies of the maximum annual heights of the wind (solid line), swell (dash line) waves, and the climatic indices

In order to analyze the correlation relations between two non-stationary processes we propose to use the wavelet correlation method - construction of crosscorrelation functions between the same frequency scales of wavelet decompositions. This simultaneously will give not only the correlation coefficients but also the frequencies (periods) at which correlation coefficients are most significant. For the first time we used this method in [11]. An example of a diagram of wavelet correlations is given in Fig. 8.

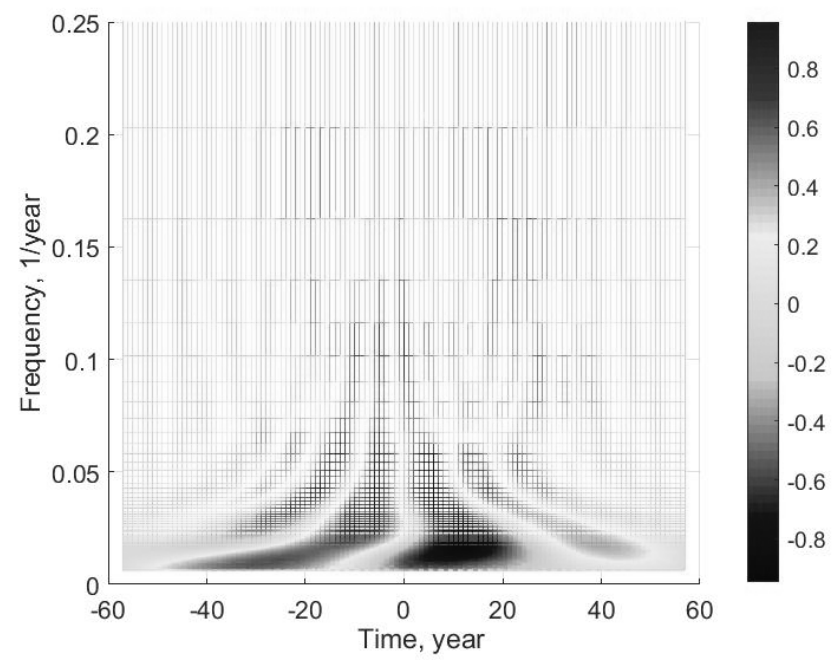

Fig. 8. Example of the wavelet correlations between the anomalies of the maximum annual heights of the wind waves and the Pacific Decadal Oscillation climatic index. The scale corresponds to the correlation coefficient values 
The changes in the wavelet correlation coefficients between the climate indices and anomalies of the maximum annual wave heights at zero time-shift by all frequency scales are shown in Fig. 9. It can be clearly seen that in general the correlation function coefficients are significantly higher than at a classical correlation analysis. The changes in anomalies of the maximum annual wind wave heights are more (moduli of correlation coefficients more than 0.50) related with $A M O$ index at 0.025, 0.04 and 0.07 1/year frequencies, with $N A O$ index - at 0.04, 0.07 and 0.16 1/year frequencies, with $P D O$ index - at 0.011 and 0.115 1/year frequencies and with $E A / W R$ index - at 0.015 and $0.03,0.06$ and 0.131 1/year frequencies.

According to wavelet correlations (Fig. 9, below), the changes in anomalies of the maximum annual swell wave heights are mostly affected by the variations of $N A O$ index (0.035, 0.06 and 0.16 1/year frequencies), $A M O$ index (0.022, 0.04, 0.06 and 0,116 1/year frequencies), $P D O$ index (0.045 and 0.081 /year frequencies) and $E A / W R(0.015,0.07$ and 0.13 1/year frequencies).
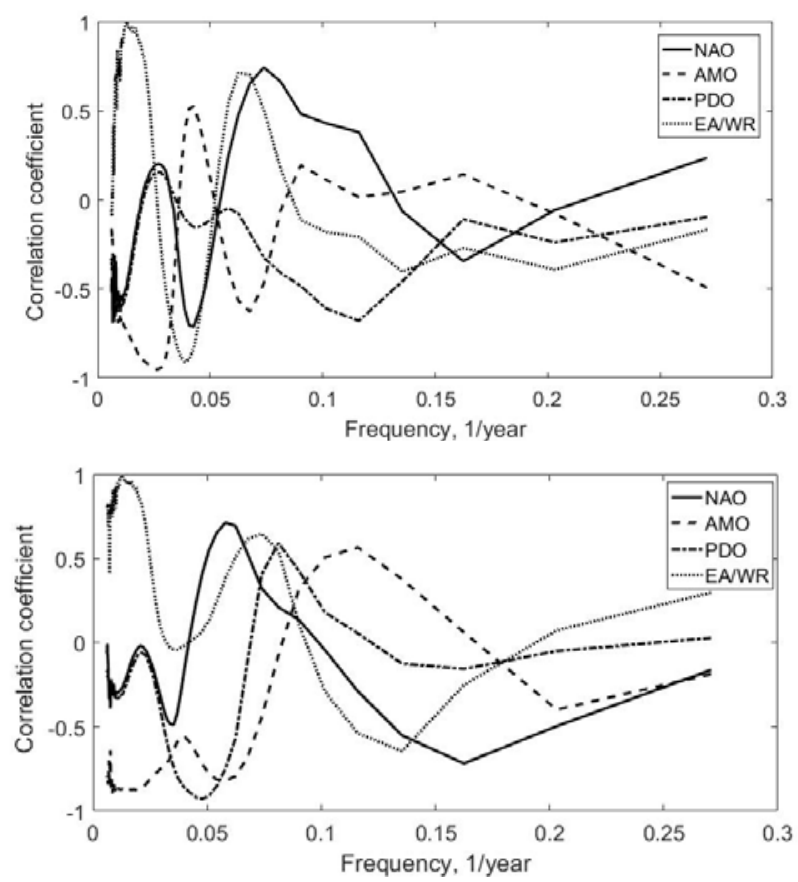

Fig. 9. Wavelet correlations between the anomalies of the maximum annual heights of the wind (above) and swell (below) waves, and the climatic indices at a zero temporal shear

Wavelet correlations also provide an estimation of time shift of climate process effect on wave climate change. Thus, for example, the greatest value of wavelet correlation coefficient modulus (0.90) between PDO index in 0.01-0.015 1/year lowfrequency range and the anomalies of the maximum heights of both wind waves and swell ones is observed with 6-8 years time shift, i. e. at great periods of $P D O$ variation (about 60-100 years) its effect on the maximum wave heights is observed with a certain delay (Fig. 8).

It should be noted that the differences between the anomalies of fluctuations of the maximum annual wind wave and swell heights and, correspondingly, between their 326

PHYSICAL OCEANOGRAPHY VOL. 25 ISS. 4 (2018) 
relations with the changes of climate indices observed during the analysis, can be explained by the fact that an array of visually registered maximum annual heights of swell waves, along with the ones of wind genesis, can also include abnormally high waves occurring with the absence of the wind, so-called rogue waves. They occur due to other mechanisms, for instance, due to modulation instability [12, 20].

In general, wavelet correlation analysis showed that the following indices have direct and equal effect on the changes of anomalies of the maximum annual wave heights (of both wins waves and swell ones):

a) $N A O$ - at $0.035-0.04,0.06-0.07$ and 0.161 /year frequencies (the periods about $25-28,14-16$ years and $6-6.5$ years);

b) $A M O$-at 0.02, 0.04 and 0.06-0.067 1/year frequencies (50, 25 periods and about $14-16$ years);

c) $P D O$-at 0.08 and 0.11 1/year frequencies (the periods about 10-12.5 года);

г) $E A / W R$-at $0.015,0.06-0.07$ and 013 1/year (the periods about 66-67, 14-16 years and $7-7.5$ years).

It should be pointed out that wavelet correlation method, unlike the classical correlation analysis, revealed a significant relationship between the changes in the wave climate and $E A / W R$ index (Fig. 7).

\section{Conclusions}

The performed analysis showed that changes in the maximum annual wave heights and climatic indices are of a complex non-stationary nature. This is due to the modulation of high-frequency fluctuations by low-frequency ones. A comparative analysis of methods for revealing the interrelations between them has shown that the methods based on wavelet analysis (particularly, spavlet analysis and wavelet correlation method) have undoubted advantages as they provide the determination non-stationary process structure, the features of period fluctuations and the interrelations with high correlation accuracy. On the basis of these methods the main periods of climate variability of the maximum annual wave height anomalies, depending on the changes in NAO, AMO, PDO and $E A / W R$ were determined. It should be noted that since the visual data array of observations of the maximum swell heights may include anomalous waves occurring due to other physical mechanisms, it is preferable to use only the wind wave data for studying the wave climate relationships with the climate indices.

\section{REFERENCES}

1. Polonskii, A.B., 2008. Atlantic Multidecadal Oscillation and its Manifestations in the Atlantic-European Region. Physical Oceanography, [e-journal] 18(4), pp. 227-236. https://doi.org/10.1007/s11110-008-9020-8

2. Bromirski, P.D. and Cayan, D.R., 2015. Wave Power Variability and Trends across the North Atlantic Influenced by Decadal Climate Patterns. Journal of Geophysical Research: Oceans. [e-journal] 120(5), pp. 3419-3443. https://doi.org/10.1002/2014JC010440

3. Galabov, V., 2015. The Black Sea Wave Energy: the Present State and the Twentieth Century Changes. Available at: https://arxiv.org/pdf/1507.01187.pdf [Accessed: 21 February 2018].

4. Polonskii, A.B., Evstigneev, V., Naumova, V. and Voskresenskaya, E.N., 2014. LowFrequency Variability of Storms in the Northern Black Sea and Associated Processes in the Ocean-Atmosphere System. Regional Environmental Change, [e-journal] 14(5), pp. 18611871. https://doi.org/10.1007/s10113-013-0546-z 
5. Vespremeanu-Stroe, A. and Tatui, F., 2005. The Influence of North Atlantic Oscillation on Romanian Black Sea Coast Wind Regimeю. In: Analele Universitatii Bucuresti. Seria Geografie. Bucureşti: Editura Universităţii din Bucureşti. An. 54. pp. 17-25. Available at: https://www.researchgate.net/profile/Alfred_Vespremeanu-

Stroe/publication/258257649_The_influence_of_North_Atlantic_Oscillation_on_Romanian_ Black_Sea_coast_wind_regime/links/00463527a23d009e7b000000/The-influence-of-NorthAtlantic-Oscillation-on-Romanian-Black-Sea-coast-wind-regime [Accessed: 21 February 2018].

6. Goryachkin, Yu.N., Zhukov, A. N., Lebedev, N.E. and Sizov, A.A., 2008. Quasi-Periodicity of the Black Sea Wind Spatial-Temporal Variability and Its Relation with the North Atlantic Oscillation Phases // Physical Oceanography, [e-journal] (5), pp. 42-50. doi:10.22449/1573160X-2017-5-42-50

7. Nesterov, E.S., 2013. Severoatlanticheskoe Kolebanie: Atmosfera i Okean [North Atlantic Oscillation: Atmosphere and the Ocean]. Moscow: Triada, 127 p. (in Russian).

8. Masselink, G., Austin, M., Scott, T., Poate, T. and Russell, P., 2014. Role of Wave Forcing, Storms and NAO in Outer Bar Dynamics on a High-Energy, Macro-Tidal Beach. Geomorphology, [e-journal] 226, pp. 76-93. https://doi.org/10.1016/j.geomorph.2014.07.025

9. Zăinescu, F.I., Tătui, F., Valchev, N.N. and Vespremeanu-Stroe, A., 2017. Storm Climate on the Danube Delta Coast: Evidence of Recent Storminess Change and Links with Large-Scale Teleconnection Patterns. Natural Hazards, [e-journal] 87(2), pp. 599-621. https://doi.org/10.1007/s11069-017-2783-9

10. Naumova, V.A., Evstigneev, M.P., Evstigneev, V.P. and Ljubarec, E.P., 2010. VetroVolnovye Usloviya Azovo-Chernomorskogo Poberezh'ya Ukrainy [Wind and Wave Forming Conditions in Azov-Black Sea Coast Region]. In: UHMI, 2010. Tr. UkrNIGMI [Scientific Works of UHMI]. Kiev: UHMI. Iss. 259, pp. 263-283. Available at: https://uhmi.org.ua/pub/np/259/Naumova-259.pdf [Accessed: 10 February 2018] (in Russian).

11. Shtremel, M., Saprykina, Y., Kuznetsov, S., Aydoğan, B.A. and Aydoğan, B., 2017. Wave Climate of the Black Sea: Visual Observations and Modelling Data. In: Proceedings of 13th International MEDCOAST Congress on Coastal and Marine Sciences, Engineering, Management and Conservation. Malta, 31 October - 4 November 2017. Millieha, Malta: Mediterranean Coastal Foundation. Vol. 2, pp. 1051-1061.

12. Grigorieva, V.G. and Badulin, S.I., 2016. Wind Wave Characteristics Based on Visual Observations and Satellite Altimetry. Oceanology, [e-journal] 56(1), pp. 19-24. https://doi.org/10.1134/S0001437016010045

13. Gulev, S.K., Grigorieva, V. and Sterl, A., 2005. Global Atlas of Ocean Waves Based on VOS Observations. [on-line] Available at: http://www.sail.msk.ru/atlas/ [Accessed: 21 February 2018].

14. Grigorieva, V.G., Gulev, S.K. and Gavrikov, A.V., 2017. Global Historical Archive of Wind Waves Based on Voluntary Observing Ship Data. Oceanology, [e-journal] 57(2), pp. 229-231. https://doi.org/10.1134/S0001437017020060

15. Stoica, P. and Moses, R., 2005. Spectral Analysis of Signals. New Jersey: Prentice Hall, 447 p. Available at: http://user.it.uu.se/ ps/SAS-new.pdf [Accessed: 21 February 2018].

16. Torrence, C. and Compo, G.P., 1998. A Practical Guide to Wavelet Analysis. Bulletin of American Meteorological Society, [e-journal] 79(1), pp. 61-78. https://doi.org/10.1175/15200477(1998)079<0061:APGTWA>2.0.CO;2

17. Vasil'ev, O.F., Savkin, V.M. and Saprykina, Ya.V., 2006. Analysis of Water Level Fluctuations in Lake Chany. Doklady Earth Sciences, [e-journal] 407(2), pp. 446-449. https://doi.org/10.1134/S1028334X06030226

18. Petenko, I.V., 2001. Advanced Combination of Spectral and Wavelet Analysis ('Spavelet' Analysis). Boundary-Layer Meteorology, [e-journal] 100(2), pp. 287-299. https://doi.org/10.1023/A:1019252617881

19. Kuznetsov, S.Yu., Saprykina, Ya.V., Kos’yan, R.D. and Pushkarev, O.V., 2006. Formation Mechanism of Extreme Storm Waves in the Black Sea. Doklady Earth Sciences, [e-journal] 408(1), pp. 570-574. https://doi.org/10.1134/S1028334X06040143 
20. Kuznetsov, S.Yu., Dulov, V.A., Saprykina, Ya.V., Dotsenko, S.F., Malinovsky, V.V., Polnikov, V.G. and Shokurov, M.V., 2011. Ekstremal'no Opasnye Shtormovye Usloviya $v$ Chernom More [Extremely Dangerous Storm Conditions in the Black Sea]. Sevastopol: MHI NAS of Ukraine, 66 p. (in Russian).

About the authors:

Yana V. Saprykina - Senior Research Associate, Shirshov Institute of Oceanology of RAS (36 Nakhimovsky Prospekt, Moscow, 117997, Russian Federation), Ph.D. (Phys.-Math.), ORCID ID: 0000-0003-0357-0773, ResearcherID: F-7556-2014, Scopus AuthorID: 6507942096, saprykina@ocean.ru

Sergey Yu. Kuznetsov - Head of V.P. Zenkovich Laboratory of the Sea Shelf and Coasts, Shirshov Institute of Oceanology of RAS (36 Nakhimovsky Prospekt, Moscow, 117997, Russian Federation), Dr.Sci. (Phys.-Math.), ORCID ID: 0000-0003-1391-1703, ResearcherID: C-63112014, Scopus AuthorID: 55179774800, kuznetsov@ocean.ru

Contribution of the co-authors:

Yana V. Saprykina - concept of the work, data collection, data analysis and interpretation, the article writing, critical revision of the article, preparation of figures, final approval of the version to be published.

Sergey Yu. Kuznetsov - data analysis and interpretation, preparation of figures, final approval of the version to be published.

All the authors have read and approved the final manuscript.

The authors declare that they have no conflict of interest. 